BMJ Nutrition, Prevention \& Health

\section{Providing food to patients in primary care to induce weight loss: a systematic literature review}

To cite: Ball L, Somerville M, Crowley J, et al. Providing food to patients in primary care to induce weight loss: a systematic literature review. BMJ Nutrition, Prevention \& Health 2021;4:e000195. doi:10.1136/ bmjnph-2020-000195

${ }^{1}$ School of Allied Health Sciences, Griffith University, Southport, Queensland, Australia ${ }^{2}$ Menzies Health Institute, Griffith University-Gold Coast Campus, Southport, Queensland, Australia ${ }^{3}$ Discipline of Nutrition and Dietetics, The University of Auckland, Auckland, New Zealand

Correspondence to Dr Lauren Ball, School of Allied Health Sciences, Griffith University, Southport, Queensland 4222, Australia; I.ball@griffith.edu.au

Received 15 October 2020 Revised 7 March 2021 Accepted 9 March 2021 Published Online First 26 March 2021
Check for updates

(C) Author(s) (or their employer(s)) 2021. Re-use permitted under CC BY-NC. No commercial re-use. See rights and permissions. Published by BMJ.

\section{ABSTRACT}

Purpose Primary care is the ideal setting to promote weight management, warranting innovative ways to support patients. This systematic review aimed to determine whether providing food to patients in primary care can help to reduce body weight.

Methods Four databases were searched for studies that aimed to elicit weight loss by directly providing foodstuffs and/or supplements to patients in primary care settings. Interventions with adults of any gender or race were included. Interventions that involved other components such as exercise classes or education sessions were excluded. The methodological quality of each study was appraised using the Effective Public Health Practice Project Quality Assessment Tool for Quantitative Studies.

Results Four heterogeneous studies met the eligibility criteria, representing 476 adults. Two studies used meal-replacement products but differed in length and intensity, another study provided green tea and vitamin $\mathrm{E}$ supplementation, and the final study provided vouchers for use at a farmers' market hosted at a primary care clinic. Interventions ranged in length from 4 to 13 weeks. Three of the four studies observed weight loss in some form and all studies observed at least one other improvement in a health outcome such as waist circumference, blood pressure or fasting insulin levels.

Conclusions A small yet notable body of literature supports the concept of providing food to patients in primary care settings to support weight loss. Further, high-quality research is needed on the efficacy and costeffectiveness of this approach to ultimately inform policy initiatives for primary care.

\section{INTRODUCTION}

Diet influences the aetiology of 7 of the 10 most globally prevalent chronic conditions. ${ }^{1}$ The avoidable negative impact of poor diet on excess body weight is also well recognised. ${ }^{2}$ The WHO recommends all countries facilitate healthy eating through primary care settings, stating it is one of the 'best buys' for improving the health of societies and enabling people to live and age well. ${ }^{1}$ Patients highly value discussions about diet during consultations with primary health professionals, ${ }^{3-7}$ however, many health professions report significant

\section{What this paper adds}

Primary care interventions that involve food provision may support weight management in patients.

- Trialled interventions are diverse in length, intensity and approach.

- There is opportunity to further investigate the costeffectiveness providing food to patients in primary care to support weight loss.

barriers to providing nutrition care including insufficient nutrition knowledge, low nutrition self-efficacy and competing priorities in consultations. $^{8-10}$ Consequently, only onethird of patients remember ever discussing nutrition during consultations, ${ }^{9}$ warranting innovative strategies that enable and support patients to eat well and manage weight.

Novel approaches to supporting healthy eating in primary care have been trialled in many countries. In the USA, telephone counselling and mailed support material have shown a small positive effect on diet but only moderate sustainability. ${ }^{11}$ In the UK, a primary care referral to a 12-month behavioural weight management programme has shown both effectiveness and costeffectiveness in reducing weight in obese patients, but is time-intensive for patients. ${ }^{12}$ In South America, group nutrition education sessions have been trialled to support large groups of patients simultaneously, but are challenged by the need for face-to-face schedules and limited clinical space. ${ }^{13}$ There is opportunity to continue to explore feasible and effective strategies to support healthy eating in primary care. ${ }^{14}$

Providing food directly to patients in primary care is one promising approach to weight management that has been underexplored. Providing foodstuffs such as portioncontrolled meals to overweight and obese adults outside of healthcare settings has revealed both clinically significant weight loss 
and increased diet quality. ${ }^{15}$ However, it is unclear whether this approach can be implemented in primary care where pragmatic considerations are needed, for example, identifying suitable patients, sourcing and storing foodstuffs. ${ }^{16}$ Thus, we undertook a systematic review to determine whether primary care interventions involving the provision of food can support weight loss and improvements in associated health outcomes.

\section{METHODS}

We undertook a systematic review following preferred reporting items for systematic reviews and meta-analyses guidelines. ${ }^{17}$ We registered the review with the PROSPERO database (CRD42020175508).

\section{Search strategy}

Peer-reviewed literature was searched in January 2020 with guidance from an experienced health librarian. We searched the following databases: CINAHL, MEDLINE, Embase and SCOPUS. The complete search strategy for each database is included as an online supplemental appendix. We cross-matched reference lists to identify additional studies for consideration. We imported all search results into EndNote and Covidence for study selection.

\section{Study selection criteria}

Figure 1 outlines study selection. We developed selection criteria using the population, intervention, comparison, outcome format. ${ }^{17}$ We used the criteria to screen, in duplicate, the titles and abstracts of literature returned via database searching. After all duplicate and non-relevant studies were excluded, we retrieved the remaining articles for full-text review. If insufficient information was found in the abstract, we considered the study again at the fulltext review stage. We resolved all discrepancies through regular discussion.

Study selection criteria included: (1) participants: ambulatory patients aged $>18$ years of any gender, ethnicity and body mass index (BMI) receiving care in a primary care setting. Studies with participants in hospital, schools, aged care or lab settings were excluded. (2) Intervention: any intervention that involved the exclusive provision of foods, ingredients, oral nutrition support or food vouchers to participants. Multifaceted interventions that did not allow for the effect of food provision to be independently assessed were excluded (eg, food provision+exercise classes). (3) Comparison: baseline, usual care, no care or minimal care that does not involve intentional weight loss strategies or the provision of food. (4) Outcomes: studies that assessed change in weight were included. (5) Study design: articles were limited to published, original research studies including intervention designs (randomised controlled trials (RCTs), nonrandomised) and pre-post studies. We included review articles on similar topics to full-text stage to screen the original studies within each review.

\section{Data extraction and synthesis}

We developed a template for data extraction to collate information from included studies. Data extracted included study details, participant details, intervention, outcome measures and key findings. Data were extracted by one researcher and checked by a second,
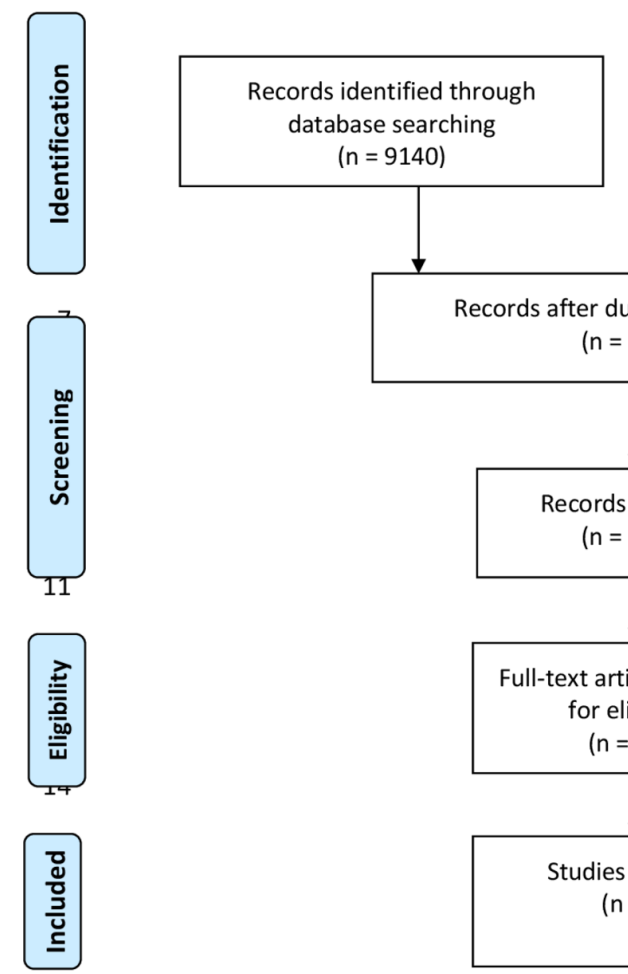

Additional records identified through other sources $(n=9140)$ $(n=4)$

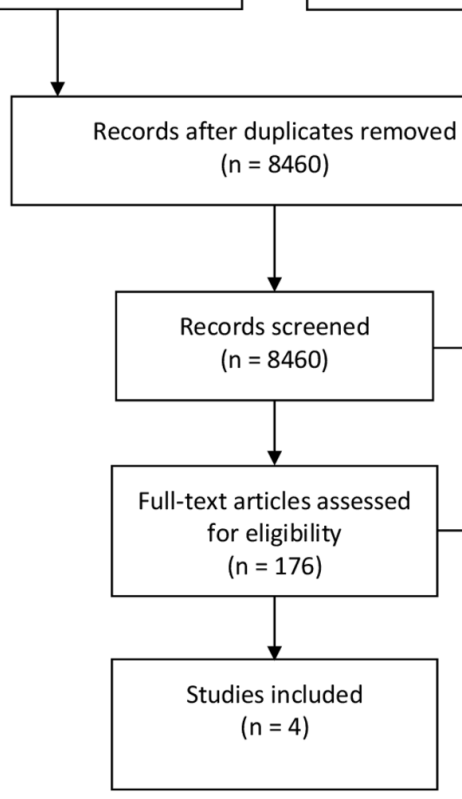

Records excluded $(n=8284)$

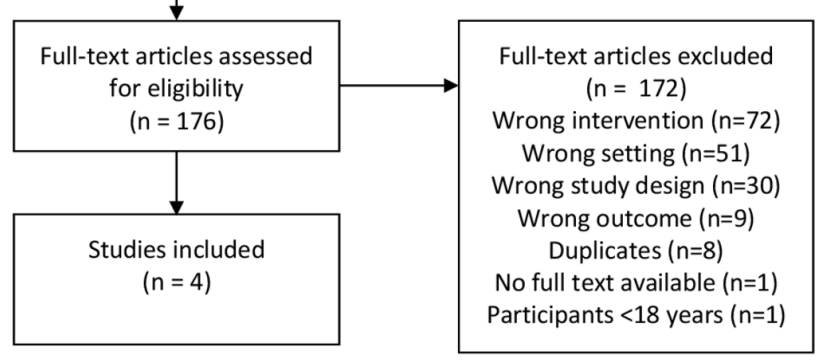

Figure 1 Study selection flowchart. 
with discrepancies resolved through discussion. We only extracted data from applicable arms of studies. If studies reported SE or $95 \%$ CIs rather than SD, we calculated SD using the Cochrane Handbook-proposed method. ${ }^{18}$ We deemed studies to have a positive overall outcome if a statistically significant reduction was reported for the weight outcome. A meta-analysis was not feasible due to the heterogeneity of included studies.

\section{Study quality assessment}

Quality assessment was conducted using the Effective Public Health Practice Project Quality Assessment Tool for Quantitative Studies. ${ }^{19}$ We selected this tool because it can assess validity of both randomised trial and prepost designs, it has documented content and construct validity, and moderate inter-rater reliability. ${ }^{20}$ The tool comprises five criteria which assess likelihood of selection bias, quality of study design, presence of confounding factors, validity and reliability of data collection, and withdrawals or dropouts. The constructs are scored as 'strong', 'moderate' or 'weak'. Each study is rated as an overview of its construct scores: 'strong' for no weak constructs; 'moderate' for one weak construct and 'weak' for two or more weak constructs. The tool considers intervention integrity and appropriateness of statistical analysis, though these do not contribute to overall study rating. ${ }^{19}$ The methodological quality of articles was appraised in duplicate and discrepancies resolved through discussion. Inter-rater agreement was assessed using Cohen's kappa for construct scores within each study and across all included studies.

\section{RESULTS}

The study selection process is illustrated in figure 1 . The initial database search identified 9140 articles. After duplicates were removed, we screened 8460 articles. The main reasons for excluding articles from further consideration were not being a relevant intervention $(n=72)$ (which included multifaceted interventions, interventions not providing foodstuffs to participants and interventions not aiming to reduce weight by providing food); or not providing care in the primary care setting $(n=51)$; or being cross-sectional in design without appropriate pre-measures and post-measures of weight $(n=30)$. Four publications fulfilled the inclusion criteria.

\section{Characteristics of included studies}

Characteristics of the four included studies are outlined in table 1 . Two of the studies were two-arm RCTs ${ }^{21} 22$ and two were pre-post studies. ${ }^{23}{ }^{24}$ We excluded data from the control arm of one RCT because it was an ineligible comparison group. ${ }^{21}$ The intervention arm was therefore treated in this review as a pre-post study. ${ }^{21}$ Two of the studies were from the USA, ${ }^{21} 23$ one from the $\mathrm{UK}^{24}$ and one from Israel. ${ }^{22}$ The studies collectively provided eligible baseline weight measures for 476 adults (range: $\mathrm{n}=22^{22}$ to $\mathrm{n}=335^{24}$ ). Dropout between baseline and follow-up ranged from $0 \%{ }^{22}$ to $38 \%{ }^{24}$ Two studies only recruited overweight or obese participants ${ }^{2124}$ and two studies did not consider BMI when screening for potential participants. ${ }^{22} 23$

\section{Intervention description}

One study provided participants with three sachets of green tea and a vitamin E supplement daily for 12 weeks, ${ }^{22}$ taken in addition to the participants' usual diet. Two studies examined the effectiveness of providing mealreplacement shakes to facilitate low-energy diets. ${ }^{21}{ }^{24}$ Of these studies, one provided participants with three shakes per day for 30 days, replacing all meals with no extra food to be consumed. ${ }^{24}$ The second meal replacement study provided two shakes per day for 12 weeks (replacing two meals, and allowing participants to prepare and consume one meal each day) followed by one shake per day for a further 10 weeks (replacing one meal, allowing participants to prepare and consume two meals each day). ${ }^{21}$ The final study hosted a 'farmers' market' at the primary care clinic for 13 weeks and provided participants with vouchers (US\$10) to purchase fresh food for consumption as part of their usual diet and requested participants complete a goals worksheet to guide programme participation. ${ }^{23}$

\section{Results of individual studies}

Table 2 outlines the baseline and follow-up weight data for each study as well as other relevant primary and secondary outcome measures.

\section{Weight loss}

Three of the four studies observed weight loss among participants. While some standard conversions could be made to align data where possible (eg, lbs to $\mathrm{kg}$ ), all studies reported results using varied units and descriptors, making comparisons challenging. In the RCT that provided green tea and vitamin E supplementation, both the intervention and control groups observed significant reductions in weight (intervention mean $76.8 \pm 10.3 \mathrm{~kg}$ at week 0 to mean $73.4 \pm 9.9 \mathrm{~kg}$ at week $12 ; \mathrm{p}=0.004$; control mean $76.2 \pm 7.6 \mathrm{~kg}$ at week 0 to mean $74.5 \pm 8.0 \mathrm{~kg}$ at week 12; $\mathrm{p}=0.004$ ), with no significant difference reported between groups. ${ }^{22}$ In the pre-post study where community pharmacists delivered a meal replacement programme, participants lost a significant amount of weight during the active phase (12 weeks) (mean loss $-4.90 \pm 0.30 \mathrm{~kg}$, $\mathrm{p}<0.0001) .{ }^{21}$ Using intention-to-treat (ITT) analysis, the average percentage loss was $5.98 \%$ of initial body weight across the first 12 weeks of the study. ${ }^{21}$ The second pre-post study that used a meal-replacement product reported a reduction in weight but failed to report if the weight loss was statistically significant. ${ }^{24}$ In this study, the average weight loss among trial completers was $6.6 \mathrm{~kg}$ with best results achieved by those participants who completed the 30-day trial and visited their doctor weekly $(7.2 \mathrm{~kg}$ weight loss).${ }^{24}$ In the farmers' market study, no significant 


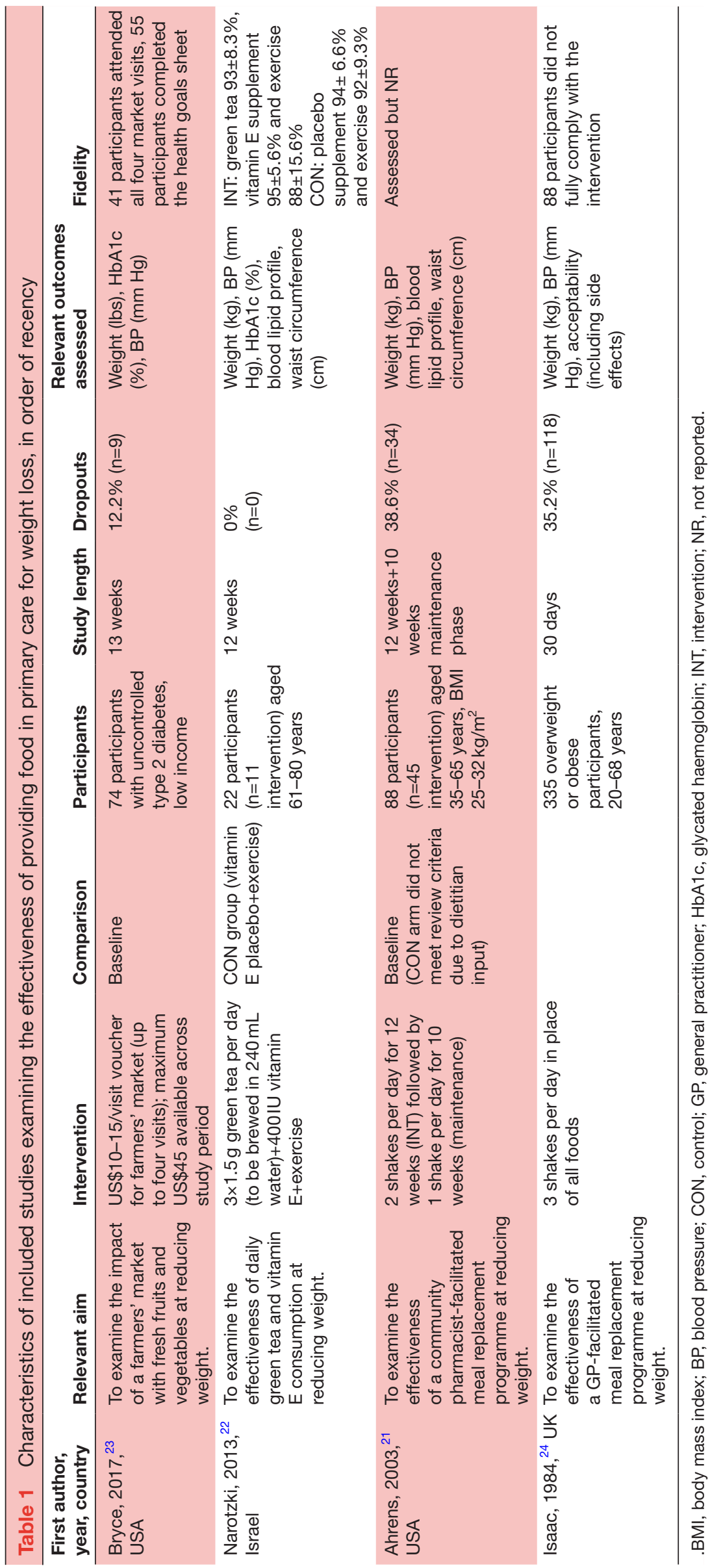


Table 2 Results of included studies examining the effectiveness of providing food in primary care to reduce weight in patients, in order of recency

\begin{tabular}{|c|c|c|c|c|c|c|}
\hline \multirow{2}{*}{$\begin{array}{l}\text { First author, } \\
\text { year, country }\end{array}$} & \multirow{2}{*}{ Weight results } & \multirow{2}{*}{ Significance } & \multicolumn{4}{|c|}{ Other outcome measures } \\
\hline & & & $\mathrm{BP}$ & Blood lipids & Waist circumference & $\mathrm{HbA1c}$ \\
\hline $\begin{array}{l}\text { Bryce, 2017, } \\
\text { USA }\end{array}$ & $\begin{array}{l}\text { Baseline: } \\
208.3 \text { lbs (94.68 kg) } \\
\text { Follow-up: } \\
209.0 \text { lbs ( } 95 \mathrm{~kg}) \\
\text { Percentage change: } \\
+0.3\end{array}$ & $\begin{array}{l}\text { No difference } \\
\text { between baseline } \\
\text { and follow-up } \\
\text { observed ( } p>0.05 \text { ) }\end{array}$ & $\begin{array}{l}\text { No significant } \\
\text { change from } \\
\text { baseline to } \\
\text { follow-up for SBP } \\
(p=0.70) \text { or DBP } \\
(p=0.17)\end{array}$ & NA & NA & $\begin{array}{l}\text { Significant } \\
\text { reduction in mean } \\
\text { HbA1c from } \\
9.54 \% \text { to } 8.83 \% \\
\text { (t-score }=3.54 \text {, } \\
p=0.001)\end{array}$ \\
\hline $\begin{array}{l}\text { Isaacs, } 1984,{ }^{24} \\
\text { UK }\end{array}$ & $\begin{array}{l}\text { Baseline: } \\
88.93 \pm 15.5 \mathrm{~kg} \\
\text { Follow-up: } \\
82.27 \pm 14.9 \mathrm{~kg} \\
\text { Percentage change: } \\
-7.5\end{array}$ & $\begin{array}{l}\text { Significance of } \\
\text { change NA }\end{array}$ & $\begin{array}{l}\text { Those who } \\
\text { completed the } \\
\text { trial and had } \\
\text { initial } \\
\text { DBP }>90 \mathrm{~mm} \\
\text { Hg observed } \\
\text { a significant } \\
\text { reduction in mean } \\
\text { BP (baseline } \\
158 / 101 \text {, follow- } \\
\text { up } 145 / 89 \text {, } \\
\text { p }<0.0001 \text { ) }\end{array}$ & NA & NA & NA \\
\hline
\end{tabular}

BP, blood pressure; CON, control; DBP, diastolic blood pressure; HbA1c, glycated haemoglobin; HDL-C, high-density lipoprotein cholesterol; INT, intervention; LDL-C, low-density lipoprotein cholesterol; NA, not assessed; NR, not reported; SBP, systolic blood pressure; TC, total cholesterol; TG, triglycerides.

change in body weight was reported between baseline and 13 weeks $(\mathrm{p}=0.45){ }^{23}$

\section{Health outcomes}

All studies reported secondary health outcomes. In the RCT that provided green tea and vitamin E supplementation, a significant decrease in fasting insulin levels was observed between baseline and week 12 for both groups (intervention $-22.2 \pm 25.5 \%, \mathrm{p}=0.016$; control $-25.2 \pm 28.5 \%, \mathrm{p}=0.015) .{ }^{22} \mathrm{~A}$ reduction in fasting glucose (intervention $-5.9 \pm 5.6 \%, \mathrm{p}=0.005$; control $+4.9 \pm 9.0 \%$, $\mathrm{p}>0.05)$ and waist circumference for both men and women (intervention men $-3.8 \pm 3.4 \%$, $\mathrm{p}=0.026$; intervention women $-11.2 \pm 3.1 \%, \mathrm{p}=0.005$, respectively) was seen in the intervention group. ${ }^{22}$ Blood pressure, $\mathrm{C}$ reactive protein and serum lipids did not change throughout the study in either group or between groups. ${ }^{22}$ Dietary intakes (ie, macronutrient distribution, vitamin $\mathrm{E}$ intake, vitamin $\mathrm{C}$ intake and kilojoule intake) also did not change significantly within or between groups.

In the pre-post study where community pharmacists delivered a meal replacement programme, improvements were observed (but no statistical testing reported) at the end of 12 weeks (weight loss phase) and 22 weeks (weight maintenance phase) for waist circumference $(-5.31 \mathrm{~cm}$ and $-8.08 \mathrm{~cm}$, respectively), systolic blood pressure $(-5.91 \mathrm{~mm} \mathrm{Hg}$ and $-8.26 \mathrm{~mm} \mathrm{Hg})$ and diastolic blood pressure $(-4.16 \mathrm{~mm} \mathrm{Hg}$ and $-5.97 \mathrm{~mm} \mathrm{Hg}) .{ }^{21} \mathrm{No}$ improvements were observed by the end of the study for triglyceride levels $(-0.08 \mathrm{mg} / \mathrm{dL}$ and $0.00 \mathrm{mg} / \mathrm{dL}$, respectively), total cholesterol $(-11.95 \mathrm{mg} / \mathrm{dL}$ and $4.74 \mathrm{mg} /$ $\mathrm{dL}$, respectively), high-density lipoprotein cholesterol $(-0.19 \mathrm{mg} / \mathrm{dL}$ and $4.44 \mathrm{mg} / \mathrm{dL}$, respectively) or 


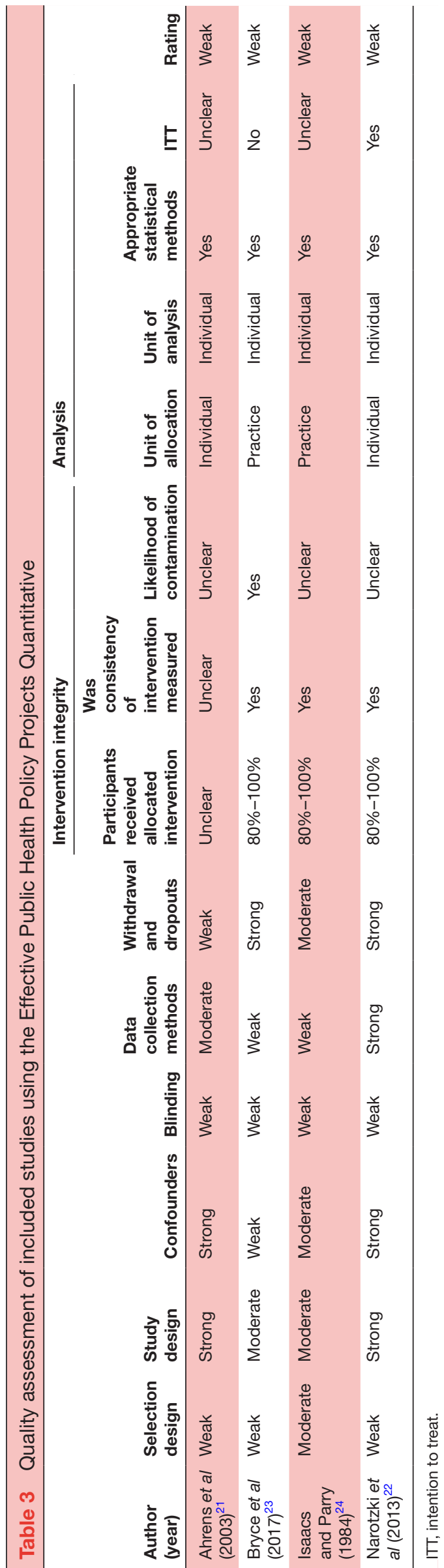

low-density lipoprotein cholesterol levels $(-8.86 \mathrm{mg} / \mathrm{dL}$ and $1.15 \mathrm{mg} / \mathrm{dL}$, respectively). ${ }^{21}$

The second pre-post study that used a mealreplacement product saw nearly two-thirds of the participants with initially hypertension became normotensive (45 of the 73 patients with an initial diastolic blood pressure recording above $90 \mathrm{~mm} \mathrm{Hg}$ ), but no other changes in health outcomes were assessed. ${ }^{24}$ In the farmers' market study, a significant decrease in glycated haemoglobin (HbA1c) was observed 3 months after the 13-week study period (mean $9.54 \%$ to mean $8.83 \%$, t-score 3.54 , $\mathrm{p}=0.001$ ) but no significant changes were reported for systolic or diastolic blood pressure. ${ }^{23}$

\section{Attrition and safety}

Attrition and side effects varied between the studies. In the RCT that provided green tea and vitamin E supplementation, compliance with green tea and vitamin E consumption was $93 \pm 8.3 \%$ and $95 \pm 5.6 \%$, respectively. In the control group, the placebo supplement compliance was $94 \pm 6.6 \%$. The level of vitamin E intake, $400 \mathrm{IU} /$ day, was based on literature that less than $1000 \mathrm{IU} /$ day is safe in healthy individuals. ${ }^{22}$ In the study that used community pharmacists to deliver a meal replacement programme, a dropout rate was reported for the total study rather than the arm that was included for review, as $23 \%$ for the active weight loss phase (two shakes per day), and a further $19 \%$ during the weight maintenance phase (one shake per day). ${ }^{21}$ Major reasons reported for attrition were time constraints and loss to follow-up, while only two participants reported intolerance to the meal-replacement shakes. $^{21}$

The Modifast product used in the second pre-post study that used a meal replacement was rated on average 'tolerable', but side effects, although, generally minor and transient, were reported by 110 participants $(32.8 \%)$ and significantly affected their ability to complete the trial. ${ }^{24}$ Side effects were reported by $21.7 \%$ of those who completed the trial successfully, $30.7 \%$ of those who lapsed during the trial $(26.3 \%, \mathrm{n}=88)$ and $42.4 \%$ among those who did not complete the trial $(25.3 \%, \mathrm{n}=118) .{ }^{24}$ In the farmers' market study, most participants $(63.1 \%, \mathrm{n}=41)$ attended the required four market visits and of these, $84.6 \%$ (55 of 65) completed their health goals sheet and received a US $\$ 5$ incentive voucher. ${ }^{23}$ No adverse events or concerns were reported for hosting the farmers' market at the primary care clinic. ${ }^{23}$

\section{Quality appraisal}

Table 3 describes the methodological quality of each study. All studies were rated as 'weak'. ${ }^{21-24}$ Common weaknesses related to blinding of participants and outcome assessors, ${ }^{21-24}$ use of non-validated tools for data collection or lack of data collection tool description, ${ }^{23} 24$ and potential selection bias. ${ }^{21-23}$ Most studies poorly described the intervention and steps taken to avoid contamination. ${ }^{212224}$ While statistical methods appeared appropriate for all study designs, there was inconsistent reporting of 
results within studies, ${ }^{21}{ }^{24}$ poor descriptions of the study groups, ${ }^{21} 2324$ and low use or poor application of ITT analysis. ${ }^{21} 2324$ Agreement for overall study ratings was $100 \%$. Inter-rater reliability for assessment of constructs within studies was moderate to substantial $(\mathrm{K}=0.44-0.72)$. Overall construct agreement was moderate $(\mathrm{K}=0.58)$.

\section{DISCUSSION}

This review explored the concept of providing food to patients in primary care as a means of supporting weight loss. Primary care is regarded as an ideal setting to support healthy eating and weight management, ${ }^{1}$ but notable barriers often prevent health professionals addressing nutrition and weight during routine care. ${ }^{8-10}$ The body of literature on this topic is notably small, with only four studies eligible for this review. ${ }^{21-24}$ There is clear opportunity for further research that advances the understanding gained from these four studies and ultimately inform policy initiatives for providing food to support weight loss and improvements in other health outcomes.

The use of meal replacements to initiate weight loss in overweight patients has potential in the general practice setting for patients who desire structured weight loss programmes. Some potentially relevant studies were not included in our review due to the heavy reliance on education. ${ }^{25} 26$ Significant weight loss and other improvements in biomarkers of disease were observed for both meal replacement studies. Commercial mealreplacement products have been shown in one review to be a convenient, often low-cost means of supplying nutritionally dense, yet low-energy meal options, which when combined with low-fat self-selected meals, significantly improves weight loss and provides a safe and effective method for maintaining that weight loss. ${ }^{27}$ While the review did not restrict studies to those conducted in primary care, a recognised challenge of incorporating meal replacements into usual care is low tolerance and acceptability. ${ }^{27}$ Further research is required to investigate the suitability and likely uptake of meal replacements in primary care clinics and the potential cost-effectiveness for reducing weight-related morbidity.

In the green tea and vitamin E supplement study, improved exercise capacity was followed by a significant reduction in body weight and fasting insulin levels in all participants. ${ }^{22}$ Even though both the intervention and control groups lost weight in the trial, the small sample size means an effect may still be possible. Polyphenolic compounds present in green tea catechins are thought to influence sympathetic nervous system activity, increasing energy expenditure and promoting the oxidation of fat, which may explain the weight loss. ${ }^{28}$ Additionally, caffeine which is naturally present in green tea also influences sympathetic nervous system activity, and may act synergistically to increase energy expenditure and fat oxidation. ${ }^{28}{ }^{29} \mathrm{In}$ a recent systematic review of the effects of green tea with 1945 participants for 12-13 weeks, weight loss was small and statistically insignificant, and viewed by the authors as unlikely to be clinically important. ${ }^{29}$ Further studies are required to investigate whether the positive outcomes may stem from green tea or vitamin $\mathrm{E}$ and the potential benefits and cost-effectiveness of green tea and vitamin $\mathrm{E}$ supplementation to initiate weight loss among overweight/obese patients in primary care.

Fruit and vegetable markets are currently being investigated in Australia as a novel approach to support fruit and vegetable consumption among disadvantaged populations and those affected by restrictions imposed from the coronavirus pandemic. ${ }^{30}$ Although the Bryce et al study did not observe significant weight loss as a result of vouchers for a local farmers' market being incorporated into routine care, a significant decrease in the HbA1C concentrations was reported, suggesting that the intervention may have had overall benefits. ${ }^{23}$ However, a notable limitation is that the cost of implementing this intervention and the sustainability of the intervention were not examined. While the study in this review did not actually measure change in food intake as a result of farmers' market vouchers, the benefits of increased fruit and vegetable consumption from shopping at local farmers' markets have been reported in other similar studies with specific populations such as lowincome patients with type 2 diabetes. ${ }^{31}$ Modest financial vouchers provided to low-income adults in urban areas have been shown to be an effective incentive to shop at farmers' markets. ${ }^{32}{ }^{33}$ Financial hardship is recognised as one key reason for poor diets (ref). ${ }^{34}$ Given these challenges, the findings of the farmers' market study demonstrate the multifaceted potential benefit of a food prescription programme for disadvantaged populations to contribute to improved health outcomes. Future studies should investigate the impact of food provision on measures of food security, access and affordability as well as dietary quality and acceptability.

The acceptability and unintended consequences of providing food to patients in primary care warrant consideration. This review excluded studies that had an educational focus, which could provide an ethical barrier to providing foodstuffs. Future studies should clearly describe the components of interventions to better investigate the impact on outcome measures. Side effects such as constipation were apparent in one of the studies that used meal-replacement products, ${ }^{24}$ but were monitored more carefully in the other. ${ }^{21}$ However, patient dropout from the meal replacement study that used pharmacists was high: ranging $28 \%$ in the weight loss phase to $42 \%$ during weight maintenance. ${ }^{21}$ High dropout is not uncommon in weight loss studies due to the challenge of behaviour change. ${ }^{35}$ Attrition can be reduced through structured, planned meals that require little participant choice; though ironically, long term this may result in flavour fatigue 
and dropout. ${ }^{36}$ High levels of dropout in weight loss studies highlight the need to employ appropriate ITT analyses, meaning dropouts are not excluded from final measures of effectiveness. Both studies in this review that used meal replacements employed ITT analyses for weight $\operatorname{loss}^{2124}$ though also reported nonITT analyses for weight loss, ${ }^{21} 24$ weight maintenance ${ }^{21}$ and other health outcomes ${ }^{21} 24$ which reflects efficacy rather than effectiveness. Overall, a small yet notable body of literature supports the concept of providing food to patients in primary care settings to support weight loss. Further, high-quality research is needed on the efficacy and cost-effectiveness of this approach to ultimately inform policy initiatives for primary care.

Correction notice The article has been corrected since it was published online. One of the co-author's name was mispelled; Mari Sommerville is now ammended to Mari Somerville.

\section{Twitter Lauren Ball @laurenball01}

Acknowledgements The authors would like to thank the Griffith University Health librarian for their support in finalising the database searches. The authors would also like to thank Dr Peter Collins for his early contributions to the conceptualisation of the review.

Contributors LB conceptualised the study, all authors contributed to the PROSPERO registration. MS designed and conducted the search. All authors screened studies for inclusion. MS and ZC contributed to data extraction. KB provided a third perspective where required. LB, MS and JC drafted the manuscript. All authors reviewed and approved the final manuscript.

Funding This project was supported by an Australian National Health and Medical Research Council grant (APP1173496).

Competing interests None declared.

Patient consent for publication Not required.

Provenance and peer review Not commissioned; externally peer reviewed by Elaine Macaninch, Education and Research in medical Nutrition Network, UK and Dr Emmanuel Baah, University of North Carolina System.

Data availability statement All data relevant to the study are included in the article or uploaded as supplemental information.

Supplemental material This content has been supplied by the author(s). It has not been vetted by BMJ Publishing Group Limited (BMJ) and may not have been peer-reviewed. Any opinions or recommendations discussed are solely those of the author(s) and are not endorsed by BMJ. BMJ disclaims all liability and responsibility arising from any reliance placed on the content. Where the content includes any translated material, BMJ does not warrant the accuracy and reliability of the translations (including but not limited to local regulations, clinical guidelines, terminology, drug names and drug dosages), and is not responsible for any error and/or omissions arising from translation and adaptation or otherwise.

Open access This is an open access article distributed in accordance with the Creative Commons Attribution Non Commercial (CC BY-NC 4.0) license, which permits others to distribute, remix, adapt, build upon this work non-commercially, and license their derivative works on different terms, provided the original work is properly cited, appropriate credit is given, any changes made indicated, and the use is non-commercial. See: http://creativecommons.org/licenses/by-nc/4.0/.

ORCID iD

Lauren Ball http://orcid.org/0000-0002-5394-0931

\section{REFERENCES}

1 World Health Organization. Tackling NCDs: 'Best buys' and other recommended interventions for the prevention and control of noncommunicable diseases, 2017.

2 Lim SS, Vos T, Flaxman AD, et al. A comparative risk assessment of burden of disease and injury attributable to 67 risk factors and risk factor clusters in 21 regions, 1990-2010: a systematic analysis for the global burden of disease study 2010. The Lancet 2012;380:2224-60.

3 Ball L, Hughes R, Desbrow B, et al. Patients' perceptions of nutrition care provided by general practitioners: focus on type 2 diabetes. Fam Pract 2012;29:719-25.

4 Ball L, Davmor R, Leveritt M, et al. Understanding the nutrition care needs of patients newly daignosed with type 2 diabetes; a need for open communication and patient-focused consulations. Australian Journal of Primary Health $0 ; 2015$. In Press.

5 Ball L, Desbrow B, Leveritt M. An exploration of individuals' preferences for nutrition care from Australian primary care health professionals. Aust J Prim Health 2014;20:113-20.

6 Fraser SE, Leveritt MD, Ball LE. Patients' perceptions of their general practitioner's health and weight influences their perceptions of nutrition and exercise advice received. J Prim Health Care 2013;5:301-7.

7 Mold F, Forbes A. Patients' and professionals' experiences and perspectives of obesity in health-care settings: a synthesis of current research. Health Expect 2013;16:119-42.

8 Crowley J, Ball L, Wall C, et al. Nutrition beyond drugs and devices: a review of the approaches to enhance the capacity of nutrition care provision by general practitioners. Aust J Prim Health 2012;18:90-5.

9 Harris MF, Fanaian M, Jayasinghe UW, et al. What predicts patientreported GP management of smoking, nutrition, alcohol, physical activity and weight? Aust J Prim Health 2012;18:123-8.

10 Ball L, Hughes R, Leveritt M. Health professionals' views of the effectiveness of nutrition care in general practice setting. Nutrition Dietetics. In Press 2013;70:35-41.

11 Fries E, Edinboro P, McClish D, et al. Randomized trial of a lowintensity dietary intervention in rural residents: the rural physician cancer prevention project. Am J Prev Med 2005;28:162-8.

12 Ahern AL, Wheeler GM, Aveyard P, et al. Extended and standard duration weight-loss programme referrals for adults in primary care (wrap): a randomised controlled trial. Lancet 2017;389:2214-25.

13 Pava-Cárdenas A, Vincha KRR, Vieira VL, et al. Promoting healthy eating in primary health care from the perspective of health professionals: a qualitative comparative study in the context of South America. BMC Nutr 2018;4:34.

14 Bhattarai N, Prevost AT, Wright AJ, et al. Effectiveness of interventions to promote healthy diet in primary care: systematic review and meta-analysis of randomised controlled trials. BMC Public Health 2013;13:1203.

15 Ptomey LT, Willis EA, Goetz JR, et al. Portion-controlled meals provide increases in diet quality during weight loss and maintenance. $J$ Hum Nutr Diet 2016;29:209-16.

16 Foy R, Eccles M, Grimshaw J. Why does primary care need more implementation research? Fam Pract 2001;18:353-5.

17 Moher D, Liberati A, Tetzlaff J, et al. Preferred reporting items for systematic reviews and meta-analyses: the PRISMA statement. Public Library of Science and Medicine 2009;6.

18 Cochrane Training. Cochrane Handbook for systematic reviews of interventions.

19 Nea E. A systematic review of rural development research. SpringerBriefs in Public Health: Appendix A: Effective Public Health Practice Project (EPHPP) Quality Assessment Tool for Quantitative Studies., 2015.

20 Armijo-Olivo S, Stiles CR, Hagen NA, Biondo PD, et al. Assessment of study quality for systematic reviews: a comparison of the Cochrane collaboration risk of bias tool and the effective public health practice project quality assessment tool: methodological research. J Eval Clin Pract 2012;18:12-18.

21 Ahrens RA, Hower M, Best AM. Effects of weight reduction interventions by community pharmacists. J Am Pharm Assoc 2003;43:583-9.

22 Narotzki B, Reznick AZ, Navot-Mintzer D, et al. Green tea and vitamin $E$ enhance exercise-induced benefits in body composition, glucose homeostasis, and antioxidant status in elderly men and women. J Am Coll Nutr 2013;32:31-40.

23 Bryce R, Guajardo C, Ilarraza D, et al. Participation in a farmers market fruit and vegetable prescription program at a federally qualified health center improves hemoglobin A1c in low income uncontrolled diabetics. Prev Med Rep 2017;7:176-9.

24 Isaacs AJ, Parry PS. A clinical assessment of Modifast in U.K. general practice. Postgrad Med J 1984;60:74-82.

25 Foster GD, Wadden TA, Lagrotte CA, et al. A randomized comparison of a commercially available portion-controlled weight-loss intervention with a diabetes self-management education program. Nutr Diabetes 2013;3:e63-e.

26 Conceição de Oliveira M, Sichieri R, Sanchez Moura A. Weight loss associated with a daily intake of three apples or three pears among overweight women. Nutrition 2003;19:253-6. 
27 Astbury NM, Piernas C, Hartmann-Boyce J, et al. A systematic review and meta-analysis of the effectiveness of meal replacements for weight loss. Obes Rev 2019;20:569-87.

28 Rains TM, Agarwal S, Maki KC. Antiobesity effects of green tea catechins: a mechanistic review. J Nutr Biochem 2011;22:1-7.

29 Jurgens TM, Whelan AM, Killian L, et al. Green tea for weight loss and weight maintenance in overweight or obese adults. Cochrane Database Syst Rev 2012;12:CD008650.

30 VicHealth. Partnership grants: more Melburnians to access affordable fruit and VEG thanks to \$150k funding boost, 2020. Available: https://www.vichealth.vic.gov.au/media-and-resources/ media-releases/more-melburnians-to-access-affordable-fruit-andveg-thanks-to-funding-boost

31 Huckfeldt PJ, Meeker D, Peters A, et al. Diabetes management for low-income patients in Los Angeles: two strategies improved disease control in the short term. Health Aff 2012;31:168-76.
32 Baronberg S, Dunn L, Nonas C, et al. The impact of new York City's health bucks program on electronic benefit transfer spending at farmers markets, 2006-2009. Prev Chronic Dis 2013;10:E163.

33 Young CR, Aquilante JL, Solomon S, et al. Improving fruit and vegetable consumption among low-income customers at farmers markets: Philly food bucks, Philadelphia, Pennsylvania, 2011. Prev Chronic Dis 2013;10:E166.

34 Hendrickson D, Smith C, Eikenberry N. Fruit and vegetable access in four low-income food deserts communities in Minnesota. Agric Human Values 2006;23:371-83.

35 Heber D, Ashley JM, Wang HJ, et al. Clinical evaluation of a minimal intervention meal replacement regimen for weight reduction. J Am Coll Nutr 1994;13:608-14.

36 Wing RR, Jeffery RW, Burton LR, et al. Food provision vs structured meal plans in the behavioral treatment of obesity. Int $J$ Obes Relat Metab Disord 1996;20:56-62. 